This is the final peer-reviewed accepted manuscript of:

2015. Multi-Layered Scaffolds for Osteochondral Tissue Engineering: In Vitro Response of Co-Cultured Human Mesenchymal Stem Cells.. pp.1535-1545. In MACROMOLECULAR BIOSCIENCE - ISSN:1616-5187 vol. 15 Amadori, S.; Torricelli, P.; Panzavolta, S.; Parrilli, A.; Fini, M.; Bigi, A.

The final published version is available online at: DOI:10.1002/mabi.201500165

Rights / License:

The terms and conditions for the reuse of this version of the manuscript are specified in the publishing policy. For all terms of use and more information see the publisher's website. 


\title{
Multi-Layered Scaffolds for Osteochondral Tissue Engineering: In Vitro Response of Co-Cultured Human Mesenchymal Stem Cells
}

\author{
Sofia Amadori, Paola Torricelli, Silvia Panzavolta, ${ }^{*}$ Annapaola Parrilli, \\ Milena Fini, Adriana Bigi
}

A promising strategy for osteochondral interface regeneration consists in the development of hybrid scaffolds, composed of distinct but integrated layers able to mimic the different regions of cartilage and bone. We developed multi-layered scaffolds by assembling a gelatin layer with layers containing different amounts of gelatin and hydroxyapatite nanocrystals, and using a gelatin solution (as a glue) to stick layers together. The scaffolds exhibit a high, interconnected porosity and mechanical properties varying with composition along the thickness of the scaffolds up to values of compressive stress and modulus of about 1 and $14 \mathrm{MPa}$, respectively. In vitro tests demonstrate that the different layers of the scaffolds promote chondrogenic and osteogenic differentiation of Human Mesenchimal Stem Cells (hMSC).

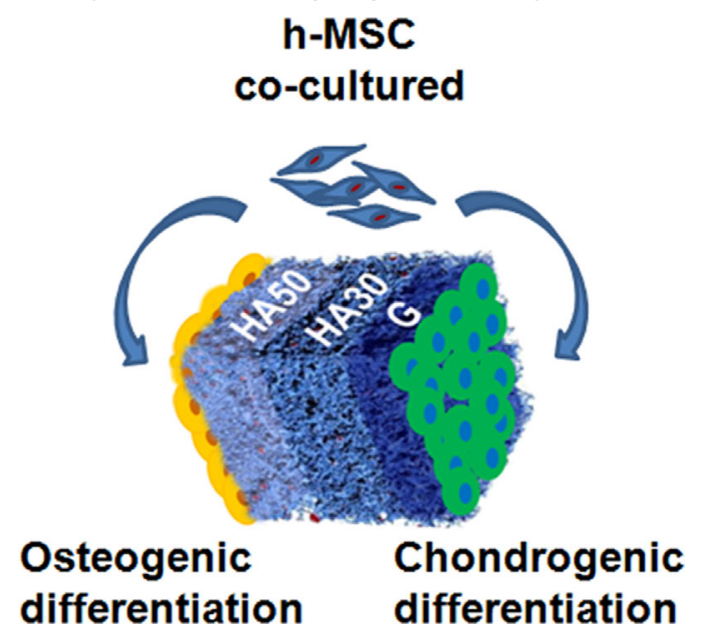

\section{Introduction}

Osteochondral lesions are very common in joints and constitute one of the major extrinsic risk factors for osteoarthritis, which causes joint pain and deformity, as well as functional disability, with significant negative impact on the quality of life. The osteochondral complex consists of two

Dr. S. Amadori, Dr. S. Panzavolta, Prof. A. Bigi

Department of Chemistry "G. Ciamician", via Selmi 240126

University of Bologna, Bologna 40126, Italy

E-mail: silvia.panzavolta@unibo.it

Dr. P. Torricelli, Dr. A. Parrilli, Dr. M. Fini

Laboratory of preclinical and surgical studies, Research Institute Codivilla Putti-Rizzoli Orthopaedic Institute, via di Barbiano, 40126, Bologna, Italy quite different tissues, articular cartilage and subchondral bone. Articular cartilage is a highly organized avascular soft tissue where the main components-water, type II collagen, and proteoglycans - are differently distributed to produce a complex structural network across the four distinct zones of cartilage ${ }^{[1]}$ It exhibits a disperse cell population and a limited capacity for self-renewal. The main components of bone tissue, which exhibits a compressive modulus higher than that of cartilage, are collagen type I, water, and a calcium phosphate similar to synthetic hydroxyapatite (HA).

Articular cartilage lesions greater than $5 \mathrm{~mm}^{2}$ do not heal spontaneously ${ }^{[2]}$ and even small subchondral defects may necessitate surgical intervention in order to prevent further degeneration and consequent osteoarthritis. ${ }^{[3]}$ An ideal repair of subchondral lesions should imply regeneration of subchondral bone and promotion of zonal restoration of cartilage 
and subchondral bone. To this aim, different biphasic or triphasic constructs have been developed with the purpose to mimic the biological structure and to achieve integration with the host tissues. ${ }^{[4-12]}$ Tissue-engineered constructs should be designed properly to interface with natural tissues from a structural, mechanical, and bio-functional point of view. ${ }^{[13,14]}$ On this basis, an osteochondral implant should have a rigid osseous layer to interface and integrate with bone tissue, and a softer chondral layer able to promote chondrocytes proliferation and deposition of cartilage extracellular matrix. Among the natural polymers, gelatin presents several advantages: it is derived from collagen, it is a low cost, biodegradable, biocompatible material, and it does not exhibit antigenicity in physiological conditions. ${ }^{[15-18]} \mathrm{We}$ recently developed highly porous 3D gelatin scaffolds reinforced with gelatin, which display very good mechanical properties and are able to promote proliferation and differentiation of primary chondrocytes derived from the human knee articular cartilage. ${ }^{[19]}$ In this study, we used gelatin reinforcement to prepare bi- and three-layered porous scaffolds through a novel, simple, and low-cost method. Characterization of the scaffolds was performed by thermogravimetric analysis (TG-DTG), scanning electron microscopy (SEM), micro-computed tomography (micro-CT), and evaluation of mechanical properties in compression. In vitro tests were performed using chondrogenic- and osteogenic-differentiated hMSC simultaneously cultured respectively on chondral and bone sides of bi- and three-layered porous scaffolds. Single cultures were performed on single-layer scaffolds for comparison. The results show that the new, highly porous, multi-layered scaffolds support the growth and improve the activity of hMSC, and that differentiated $\mathrm{hMSC}$ populations influence each other as concerns both proliferation and extracellular matrix production.

\section{Materials and Methods}

Type A gelatin (280 Bloom, Italgelatine SpA) from pig skin was used. HA synthesis was performed through drop-wise addition of an $\left(\mathrm{NH}_{4}\right)_{2} \mathrm{HPO}_{4}$ solution to a $\mathrm{Ca}\left(\mathrm{NO}_{3}\right)$
$2 \cdot 4 \mathrm{H}_{2} \mathrm{O}$ solution $(\mathrm{Ca} / \mathrm{P}$ molar ratio $=1.67)$ at $90^{\circ} \mathrm{C}$ for $4 \mathrm{~h}$. The precipitate was centrifuged, dried at $37^{\circ} \mathrm{C}$ and then finely ground in a mortar.

\subsection{Single- and Multi-Layered Scaffolds Preparation}

For the preparation of gelatin scaffolds, $130 \mathrm{~mL}$ of aqueous gelatin solution (10\% wt/V) was mechanically stirred $(\approx 600 \mathrm{rpm})$ at $55^{\circ} \mathrm{C}$ for about $5 \mathrm{~min}$ before adding $10 \mathrm{~mL}$ of an aqueous solution of genipin $0.15 \% \mathrm{wt} / \mathrm{V}$ (Wako, Japan) and $10 \mathrm{~mL}$ of a phosphate-buffered solution (PBS) $1 \mathrm{M}$ at $\mathrm{pH}$ 7.4. Then, the foam was poured on Petri dishes $(\phi=6 \mathrm{~cm})$, allowed to undergo gelation at $37^{\circ} \mathrm{C}$ for $3 \mathrm{~h}$ and successively washed in $0.1 \mathrm{M}$ glycine aqueous solution and in distilled water. Freeze-drying $\left(24 \mathrm{~h}\right.$ at $-44^{\circ} \mathrm{C}$ and $0.1 \mathrm{mBar}$ ) was carried out after the scaffolds were soaked in ethanol for $24 \mathrm{~h}^{[19]}$ Gelatin scaffolds at two different HA contents, 30 and $50 \mathrm{wt} \%$, (wt\% of HA with respect to the total weight of HA and gelatin), were prepared by adding the proper amounts of HA to $130 \mathrm{~mL}$ of a gelatin solution in order to obtain suspensions of different compositions.

In order to improve mechanical properties and stimulate cell proliferation, ${ }^{[19]}$ the different single-layer scaffolds were reinforced with a $2.5 \% \mathrm{wt} / \mathrm{V}$ gelatin solution containing $0.15 \% \mathrm{wt} / \mathrm{V}$ genipin. To this aim, samples (about $1 \times 1 \times 1 \mathrm{~cm}$, weight $=50 \mathrm{mg}$ ) were soaked into $10 \mathrm{~mL}$ of genipin/gelatin solution for $5 \mathrm{~min}$. Freeze-drying $(24 \mathrm{~h}$ at $-44^{\circ} \mathrm{C}$ and $0.1 \mathrm{mBar}$ ) was carried after removal of the excess of gelatin from the samples.

The scaffolds were labeled according to their inorganic phase content, HA30, and HA50, whereas scaffolds of pure gelatin were labeled $\mathrm{G}$.

Overlapping of single layers (about $0.3 \times 1 \times 1 \mathrm{~cm}$ ) after soaking and removal of the excess of gelatin allowed to obtain multi-layer scaffolds, where gelatin also acts as a glue between the layers (Scheme 1). Bi- and three-layered scaffolds were frozen and then lyophilized for $24 \mathrm{~h}$ at $-44^{\circ} \mathrm{C}$ and $0.1 \mathrm{mBar}$.

Multi-layer scaffolds were labeled G/HA30, G/HA50, and G/HA30/HA50.

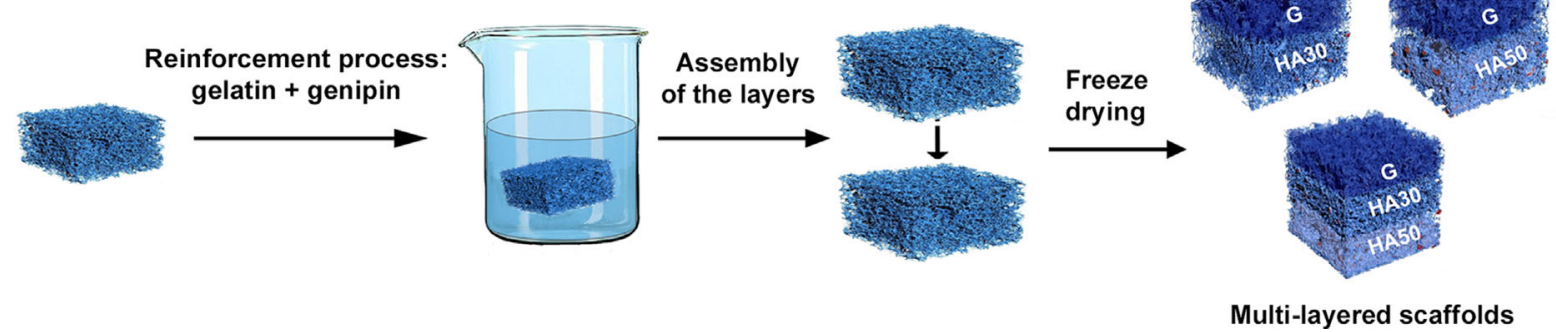

Scheme 1. Sketch of the procedure utilized to assemble bi- and three-layered scaffolds. 


\subsection{Scaffolds Characterization}

A Philips XL-20 scanning electron microscope operating at $15 \mathrm{kV}$ was used for the morphological and micro-structural characterizations of the scaffolds, which were sputtercoated with gold before examination.

A 4465 Instron testing machine, equipped with a $1 \mathrm{kN}$ load cell, was utilized for compression tests. $1 \times 1 \times 1 \mathrm{~cm}$ samples were tested at a loading rate of $1.0 \mathrm{~mm} \cdot \mathrm{min}^{-1}$ in dry conditions.

The amount of adsorbed gelatin was calculated as

$$
W \%=\frac{\left(W_{\mathrm{A}}-W_{\mathrm{B}}\right) \cdot 100}{W_{\mathrm{B}}}
$$

where $W_{\mathrm{B}}$ and $W_{\mathrm{A}}$ are the weights of the sample before $(50 \mathrm{mg})$ and after reinforcement, respectively.

The equilibrium Water Uptake Ability (WUA) was determined after immersion of the pre-weighted dry samples in PBS for $20 \mathrm{~s}$. The weight of wet sample was measured after PBS excess removal. Then, the water uptake ability was determined according to the following equation:

$$
\mathrm{WUA}=\frac{W_{\mathrm{w}}-W_{\mathrm{d}}}{W_{\mathrm{d}}}
$$

where $W_{\mathrm{w}}$ and $W_{\mathrm{d}}$ represent the weight of wet and dry sample, respectively. ${ }^{[20]}$ The process was repeated in triplicate and data were reported as mean and standard deviation.Gelatin release in PBS solution ( $\mathrm{pH} 7.4$ and $37^{\circ} \mathrm{C}$ ) was determined at increasing time, from $3 \mathrm{~h}$ to $28 \mathrm{~d}$, by colorimetric method using a bicinchoninic acid protein assay (Sigma Chemical, St. Louis, MO). ${ }^{[18]}$ Statistical analysis was performed with the Student t-test considering a $P$ value of less than 0.05 to be significantly different.

\subsection{In Vitro Study}

Human mesenchymal stem cells (hMSC, Poietics Stem Cells, Lonza Walkersville, USA) derived from bone marrow were cultured in basal medium (DMEM supplemented with 10\% FCS, and $1 \%$ antibiotics), and incubated at $37^{\circ} \mathrm{C}$ in a humidified $95 \%$ air $/ 5 \% \mathrm{CO}_{2}$ atmosphere (standard condition). At $90 \%$ confluence, cells were subcultured in osteogenic (high DMEM additioned with $\beta$-glycerophosphate $10^{-2} \mathrm{M}$, dexamethasone $10^{-4} \mathrm{M}$, and ascorbic acid $50 \mu \mathrm{g} \cdot \mathrm{mL}^{-1}$ ) or chondrogenic medium (chondrocyte differentiation medium: basal medium supplemented with TGF $\beta-3$ 1\%, R3-IGF- $10.2 \%$, insulin $0.2 \%$, transferrin $0.2 \%$, and ascorbic acid $2.5 \%$ ).

After $14 \mathrm{~d}$ of incubation in differentiating medium, chondrogenic (hMSC-C) and osteogenic (hMSC-O)-induced hMSC were counted and seeded in high-density aliquots of $20 \mu \mathrm{L}\left(2 \times 10^{5}\right.$ cells $\mathrm{mL}^{-1}$ and $1 \times 105$ cells $\cdot \mathrm{mL}^{-1}$, respectively) on experimental scaffolds in single or in coculture (hMSC-C-O) as reported in Scheme 2.

Six samples for each group and each experimental time were used. Before cell seeding, the samples were sterilized with $\gamma$ - rays $(25 \mathrm{kGy}) .{ }^{[18]}$

Cells were allowed to adhere to the scaffolds for $1 \mathrm{~h}$ in standard condition, then fresh medium was added in wells. Scaffolds were maintained in culture for 7 and $14 \mathrm{~d}$. Control groups were prepared as single (CTR-C, CTR-O) and cocultures (CTR-C-O) without materials; in CTR co-cultures, cells were seeded in direct contact for the evaluation of cell activity and proliferation, whereas transwells were used to allow also the evaluation of osteogenic and chondrogenic hMSC contribution to total viability: hMSC-O were seeded on the bottom of wells, hMSC-C in transwells.

\subsection{Cell Viability}

At the end of experimental times, cell proliferation and viability were measured by WST1 colorimetric reagent test (WST1, Roche Diagnostics GmbH, Manheim, Germany). The assay is based on the reduction of tetrazolium salt to a soluble formazan salt by a reductase of the mitochondrial respiratory chain, active only in viable cells. $100 \mu$ l of WST1 solution and $900 \mu \mathrm{l}$ of medium (final dilution: 1:10) were added to all wells, and the multi-well plates were incubated at $37^{\circ} \mathrm{C}$ for the next $4 \mathrm{~h}$. Supernatants were quantified spectrophotometrically at $450 \mathrm{~nm}$ with a reference wavelength of $625 \mathrm{~nm}$. Results of WST1 are reported as optical density (OD) and correlate directly with the cell number.

\subsection{Cell Activity and Differentiation}

For the evaluation of osteoblast and chondrocytes markers, supernatant was collected from all samples and centrifuged to remove particulates, if any. Aliquots were dispensed in Eppendorf tubes for storage at $-70^{\circ} \mathrm{C}$ and assayed for alkaline phosphatase (ALP, immunoenzymatic assay, USCN Life

\begin{tabular}{|c|c|c|c|}
\hline materials & cells & medium & samples \\
\hline G & $\begin{array}{l}\text { chondrogenic } \\
\text { differentiating } \\
\text { hMSC }\end{array}$ & $\begin{array}{l}\text { chondrogenic } \\
\text { medium }\end{array}$ & \\
\hline HA30, HA50 & $\begin{array}{l}\text { osteogenic } \\
\text { differentiating } \\
\text { hMSC }\end{array}$ & $\begin{array}{l}\text { osteogenic } \\
\text { medium }\end{array}$ & \\
\hline $\begin{array}{l}\text { G/HA30 } \\
\text { G/HA50 } \\
\text { G/HA30/HA50 }\end{array}$ & $\begin{array}{l}\text { chondrogenic } \\
\text { hMSC on the G } \\
\text { side, } \\
\text { osteogenic } \\
\text { hMSC on the } \\
\text { HA side }\end{array}$ & $\begin{array}{l}\text { chondrogenic: } \\
\text { osteogenic } \\
\text { medium } 50: 50\end{array}$ & \\
\hline
\end{tabular}
Science, Wuhan, China), Type I collagen (COLL1,

Scheme 2. Arrangement of cell seeding on the different scaffolds. 
immunoenzymatic assay, USCN Life Science), Type II collagen (COLL2, immunoenzymatic assay, USCN Life Science), and aggrecan (AGC, immunoenzymatic assay, USCN Life Science).

SEM investigation was carried out using a Philips XL-20 scanning electron microscope operating at $15 \mathrm{kV}$ on samples fixed in $2.5 \%$ glutaraldehyde, in $\mathrm{pH} 7.4$ phosphate buffer $0.01 \mathrm{M}$ for $1 \mathrm{~h}$ and dehydrated in a graded ethanol series, and sputter-coated with Pt:Pd alloy.

\subsection{Quantitative Polymerase Chain Reaction (qPCR)}

Total RNA was isolated from all samples at $24 \mathrm{~h}$ (baseline) and at $14 \mathrm{~d}$. Phenol-chloroform extraction was performed using TRIzol reagent (Invitrogen, Carlsbad, CA). Purified RNA was reverse transcribed with Superscript VILO cDNA Synthesis kit (Invitrogen, Carlsbad, CA), following manufacturer's instructions. The resulting cDNA was quantified with Quant-iT Pico-Green dsDNA assay kit (Invitrogen) and diluted to the final concentration of $5 \mathrm{ng} \cdot \mathrm{ml}^{-1}$. Each sample (10 ng) was tested in duplicate. qPCR analysis was performed in a LightCycler Instrument (Roche Diagnostics $\mathrm{GmbH}$, Mannheim, Germany) using the QuantiTect SYBR Green PCR kit (Qiagen, Hilden, Germany). The protocol included a denaturation at $94^{\circ} \mathrm{C}$ for $15^{\prime}, 35-40$ cycles of amplification $\left(94^{\circ} \mathrm{C} 15^{\prime \prime}\right.$, appropriate annealing temperature for each target as detailed in Table 1 for $20^{\prime \prime}$ and $72{ }^{\circ} \mathrm{C}$ for $\left.20^{\prime \prime}\right)$, and a melting curve to check for amplicon specificity. The crossing point values (i.e., the cycle number at which the detected fluorescence exceeded the threshold value) of each sample were used for comparative gene expression analysis employing the $2^{-\Delta \Delta C t}$ method.

\subsection{Statistical Analysis}

SPSS/PC + StatisticsTM 21 (SPSS, Inc., Chicago, IL, USA) was used for statistical evaluation of data, which are reported as mean \pm standard deviations (SD) of three independent experiments at a significance level of $p<0.05$. After having verified normal distribution and homogeneity of variance, a one-way ANOVA was done for comparison between groups. Moreover, a post-hoc multiple comparison test was performed to detect significant differences among groups and controls. Student's t-test was used for the comparison between two groups.

\section{Results and Discussion}

\subsection{Scaffolds Characterization}

Reinforcement of gelatin porous scaffolds with genipin cross-linked gelatin solution has been recently shown to greatly improve the mechanical properties of the scaffolds, which maintain an open interconnected high porosity. ${ }^{[19]}$ In this work, we exploited gelatin reinforcement to develop multi-layered porous scaffolds of graded composition for osteoarticular applications. To this aim, we produced and assembled porous gelatin layers at different HA contents.

\subsection{Single-Layer Scaffolds}

Reinforcement of the single-layer scaffolds provokes absorption of a gelatin amount which decreases from about $66 \%$ (G) to about 42 (HA30) and 24\% (HA50) on increasing HA content. The TG plot of gelatin scaffold $(G)$ displays three thermal processes: the first one, between 25 and about $200{ }^{\circ} \mathrm{C}$, is due to loss of water; the second one between 200 and $450^{\circ} \mathrm{C}$ involves gelatin decomposition, and the third one between 450 and $700^{\circ} \mathrm{C}$ is ascribed to the combustion of the residual organic component. ${ }^{[21]}$ The relative amount of inorganic phase in the HA-containing scaffolds has been determined from the residual weight of the scaffolds after the three thermal processes (Figure 1) and it amounts to about $21 \pm 1$ and $36 \pm 1$ for HA30 and HA50, respectively.

Table 1. Analyzed genes description.

\begin{tabular}{|c|c|c|c|c|}
\hline Gene & & Sequence $\left(5^{\prime}\right.$ to $\left.3^{\prime}\right)$ & Annealing temperature & Number of cycles \\
\hline \multirow[t]{2}{*}{ GAPDH } & FW & TGG TAT CGT GGA AGG ACT CA & $56^{\circ} \mathrm{C}$ & 25 \\
\hline & RV & GCA GGG ATG ATG TTC TGG A & & \\
\hline COL1A1 & \multicolumn{2}{|c|}{ Hs_COL1A1_1_SG* } & $55^{\circ} \mathrm{C}$ & 45 \\
\hline RUNX2 & \multicolumn{2}{|c|}{ Hs_RUNX2_1_SG* } & $55^{\circ} \mathrm{C}$ & 45 \\
\hline \multirow[t]{2}{*}{ ACAN } & FW & TCG AGG ACA GCG AGG CC & $60^{\circ} \mathrm{C}$ & 45 \\
\hline & RV & TCG AGG GTG TAG CGT GTA GAG A & & \\
\hline \multirow[t]{2}{*}{ SOX9 } & FW & GAG CAG ACG CAC ATC TC & $60^{\circ} \mathrm{C}$ & 45 \\
\hline & RV & CCT GGG ATT GCC CCG A & & \\
\hline
\end{tabular}

*QuantiTect Primer Assay (Qiagen). 


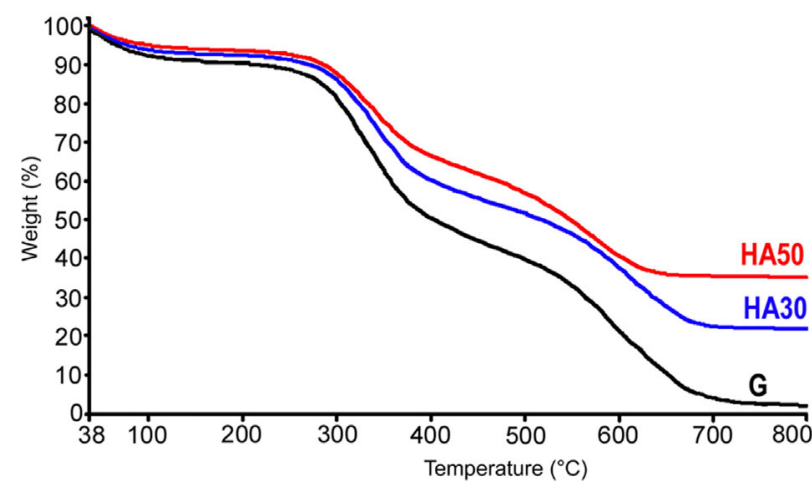

Figure 1. TG plots of the different single-layer scaffolds.

These values are consistent with the original amounts of HA used to prepare the scaffolds and the quantity of gelatin adsorbed through reinforcement.

Cross-sectional SEM images (Figure 2) show that all the different single-layer scaffolds display highly porous interconnected structures.

A quantitative evaluation of porosity has been performed through $\mu$-CT analysis. Porosity of different scaffolds is completely open and interconnected, as indicated by the results reported in Table 2. Moreover, no significant variation can be appreciated as a function of composition, suggesting that the presence of HA nanocrystals does not affect porosity parameters. At variance, the presence of the inorganic phase greatly improves the mechanical performance of the scaffolds. The compressive stress-strain curves reported in Figure 3 show distinct linear elastic, collapse plateau, and densification regimes. ${ }^{[19,22,23]}$

Table 3 reports the values of elastic modulus $(E)$, determined via linear regression of the initial linear regime, the collapse stress $(\sigma)$, and strain $(\varepsilon)$, determined by the intersection point of the linear line for calculation of $E$ and the linear regression of the collapse plateau regime $(\Delta \sigma / \Delta \varepsilon)$. The presence of HA induces a significant increase of the collapse stress, and a remarkable
Table 2. Porosity parameters of the different layers.

\begin{tabular}{lccc}
\hline Sample & P [tot] & P [op] & P [cl] \\
\hline G & $84.08 \pm 0.16$ & $84.08 \pm 0.16$ & $0.00 \pm 0.00$ \\
HA30 & $86.31 \pm 2.35$ & $86.31 \pm 2.35$ & $0.00 \pm 0.00$ \\
HA50 & $82.50 \pm 0.08$ & $82.42 \pm 0.09$ & $0.48 \pm 0.07$ \\
\hline
\end{tabular}

improvement of the elastic modulus, which exhibits a fourfold increase as the inorganic phase content passes from 0 (G) to $36 \mathrm{wt} \%$ (HA50).

HA presence also influences water uptake ability, as shown by the WUA results reported in Figure 4. WUA value measured for $\mathrm{G}$ scaffold amounts to $13.6 \pm 0.7 \mathrm{~mL} \cdot \mathrm{g}^{-1}$, and it reduces remarkably as the inorganic phase content increases, showing that this parameter depends just on the total amount of gelatin present in the samples.

It has been shown that reinforcement with genipincontaining gelatin provides scaffolds with a great stability in solution. ${ }^{[19]}$ In agreement, gelatin cumulative release from the different scaffolds amounts to about $10 \mathrm{wt} \%$ after $48 \mathrm{~h}$ in PBS and increase with time up to $21-30 \mathrm{wt} \%$ after 28 $\mathrm{d}$, in agreement with the different gelatin content of the different samples (Table 4).

\subsection{Multi-Layered Scaffolds}

Bi- and three-layered scaffolds with graded composition have been prepared by assembling and freeze-drying reinforced single-layer scaffolds. Genipin-containing gelatin reinforcement acts as a glue sticking the layers together during freeze-drying. Cross-sectional SEM images (Figure $5 \mathrm{a}-\mathrm{c}$ ) show homogeneous continuous porous structures where the junction zones cannot be clearly distinguished.

The same conclusion can be drawn from the 3D micro-CTreconstructed images reported in Figure 6 . The open and interconnected porosity does not vary significantly in the
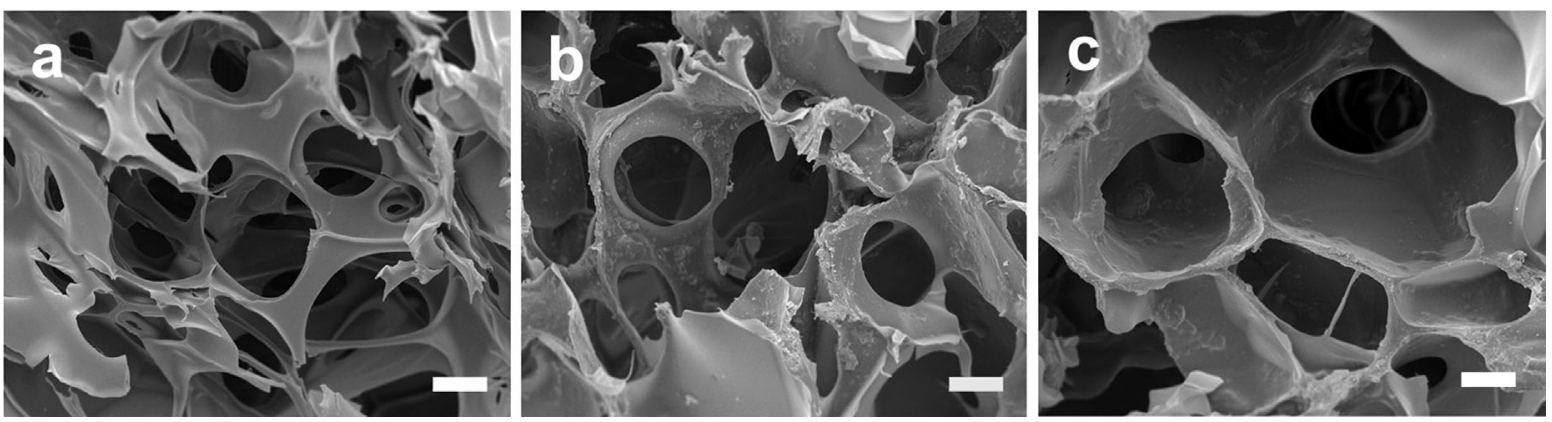

Figure 2. Cross-sectional SEM micrographs of (a) G, (b) HA3O, and (c) HA5O mono-layer scaffolds. Bars $=50 \mu \mathrm{m}$. 


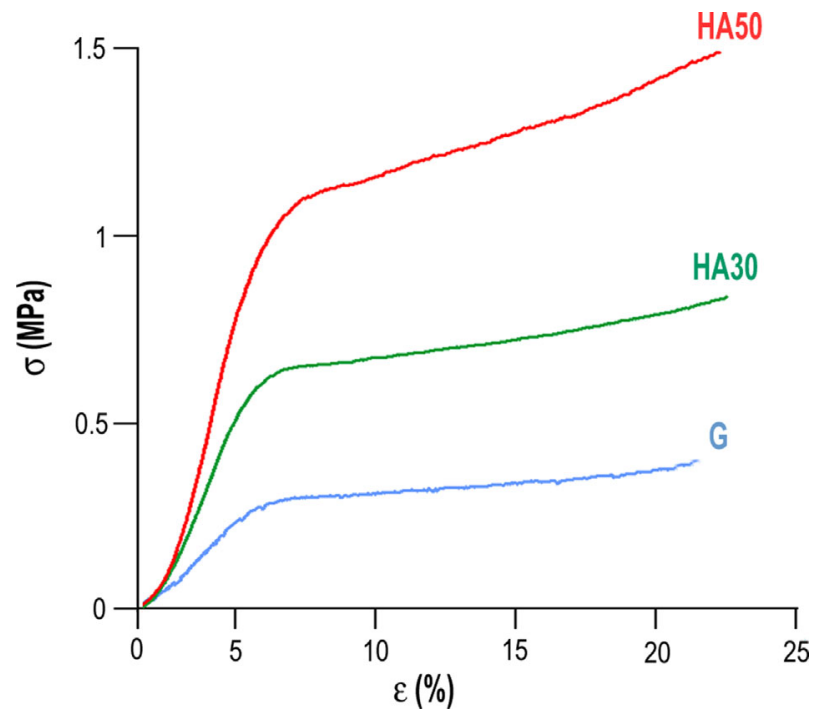

Figure 3. Typical stress-strain curves of $3 \mathrm{D}$ porous single-layer scaffolds.

different multi-layered samples, and it assumes a mean value of $85.43 \pm 3.29$, quite close to the values obtained for the single-layer scaffolds.

The resolution of the 3D images is not sufficient to appreciate the presence of the HA nanocrystals, it allows to distinguish just a few HA aggregates, which are colored in red in the 3D micro-CT reconstructions. However, EDS maps show a homogeneous distribution of calcium in the HAcontaining layers, consistent with a homogeneous distribution of the nanocrystals (Figure $5 \mathrm{~d}-\mathrm{f}$ ). The detection of phosphorous not just in the EDS maps of the HA30 and HA50 layers, but also of the $G$ layer, is due to the presence of

Table 3. Mean values of linear elastic modulus (E), collapse stress $(\sigma)$, and strain of the $3 \mathrm{D}$ scaffolds. Each value is the mean of six determinations and is reported with its standard deviation. (Student's t-test: ${ }^{\mathrm{a}} p<0.01,{ }^{\mathrm{b}} p<0.005,{ }^{\mathrm{c}} p<0.0005,{ }^{\mathrm{d}} p<0.0001$ ).

\begin{tabular}{lccc}
\hline Sample & $\boldsymbol{\sigma}[\mathbf{M P a}]$ & $\mathbf{E}[\mathbf{M P a}]$ & $\boldsymbol{\varepsilon}[\%]$ \\
\hline G & $0.3 \pm 0.1^{\mathrm{a}, \mathrm{c}}$ & $3.3 \pm 0.3^{\mathrm{c}, \mathrm{d}}$ & $11 \pm 2$ \\
HA30 & $0.60 \pm 0.07^{\mathrm{a}}$ & $7 \pm 1^{\mathrm{b}}$ & $10 \pm 1$ \\
HA50 & $1.0 \pm 0.2$ & $14 \pm 2^{\mathrm{a}}$ & $9 \pm 2$ \\
G/HA30 & $0.7 \pm 0.1$ & $8 \pm 2$ & $10 \pm 3$ \\
G/HA50 & $0.8 \pm 0.1$ & $8 \pm 1$ & $12 \pm 3$ \\
G/HA30/HA50 & $0.5 \pm 0.1$ & $5 \pm 2$ & $9 \pm 3$ \\
\hline
\end{tabular}

$\sigma:{ }^{\mathrm{a}} \mathrm{G}$ versus $\mathrm{G} / \mathrm{HA} 30 / \mathrm{HA} 50$; HA30 versus HA50 $(p<0.01) ;{ }^{\mathrm{c}} \mathrm{G}$ versus HA30, HA50, G/HA30, G/HA50 E: ' $\mathrm{G}$ versus HA30, G/HA30; ${ }^{d} G$ versus HA50, G/HA50; ${ }^{b}$ HA30 versus HA50, ${ }^{a}$ HA50 versus $G /$ HA30/HA50

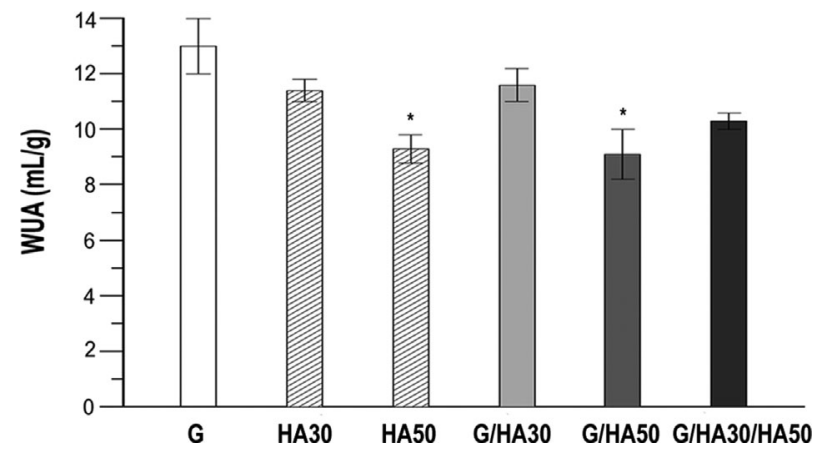

Figure 4. Water uptake ability of the different scaffolds. ${ }^{*} p<$ 0.025 , HA5O versus HA3O; G/HA5O versus G/HA3O.

PBS in the initial gelatin solution utilized to prepare the scaffolds (see Section 2.2).

Assembling into multi-layers levels off the mechanical parameters, which exhibit values intermediate between those determined for the single-layer HA30 and HA50. The values of $\sigma$ and $E$ displayed by the three-layered scaffolds are reduced, although not significantly different, with respect to the bi-layered scaffolds (Table 3 ).

The presence of junction zones does not affect the stability in solution: as a matter of fact, the data of gelatin release in PBS from bi- and three-layered scaffold do not show significant variations with respect to those obtained from single-layer scaffolds (Table 4).

WUA values determined for the multi-layered scaffolds are in agreement with those exhibited by the single-layer scaffolds and related to their different inorganic phase contents (Figure 4).

\subsection{In Vitro Tests}

Although literature reports encouraging results obtained through the use of different scaffolds and procedures, good and satisfactory clinical achievements are still limited. ${ }^{[1]}$ Finding the ideal graft for a successful clinical response is a real challenge, which stimulates a lot of studies aimed to prepare new scaffolds and to test cells of different origin. The development of hybrid scaffolds, composed of distinct but integrated layers of different materials for the cartilage and bone regions, mimicking the physiological environment of osteochondral zone, is a promising strategy for osteochondral interface regeneration. ${ }^{[2]}$ Differentiated primary osteoblasts, articular chondrocytes, and undifferentiated or differentiated after in vitro induction bone marrow mesenchymal stem cells (MSC) in various combinations have been employed for the evaluation of osteochondral scaffolds. ${ }^{[25-30]}$ Bone marrow stem cell's self-renewal ability and differentiation potentiality make them very attractive for tissue engineering and 
Table 4. Gelatin release (wt\%) from the different samples as a function of the storage time in PBS. Each value is the mean of three determinations and is reported with its standard deviation.

\begin{tabular}{|c|c|c|c|c|c|c|c|c|}
\hline \multirow[t]{2}{*}{ Samples } & \multicolumn{8}{|c|}{ Gelatin release [\%] } \\
\hline & $\mathbf{t}=\mathbf{3} \mathbf{h}$ & $t=6 \mathrm{~h}$ & $t=24 h$ & $t=48 h$ & $\mathbf{t}=\mathbf{7} \mathbf{d}$ & $t=14 d$ & $t=21 d$ & $t=28 d$ \\
\hline G & $7.9 \pm 0.1$ & $9.3 \pm 0.1$ & $10.3 \pm 0.1$ & $10.3 \pm 0.1$ & $16.0 \pm 0.1$ & $24.0 \pm 0.7$ & $27.6 \pm 0.8$ & $30 \pm 1$ \\
\hline HA30 & $8 \pm 1$ & $10.6 \pm 0.1$ & $13.3 \pm 0.1$ & $14.8 \pm 0.1$ & $18.7 \pm 0.1$ & $21.0 \pm 0.1$ & $23.0 \pm 0.3$ & $25.3 \pm 0.5$ \\
\hline HA50 & $8.8 \pm 0.8$ & $10.5 \pm 0.2$ & $11.9 \pm 0.3$ & $12.9 \pm 0.1$ & $15.9 \pm 0.3$ & $17.7 \pm 0.1$ & $19.3 \pm 0.9$ & $21.3 \pm 0.1$ \\
\hline G/HA30 & $7.7 \pm 0.7$ & $7.9 \pm 0.3$ & $9.9 \pm 0.1$ & $10.0 \pm 0.1$ & $12.7 \pm 0.8$ & $21.0 \pm 0.2$ & $25 \pm 2$ & $27.0 \pm 0.8$ \\
\hline G/HA50 & $6.1 \pm 0.8$ & $6.9 \pm 0.1$ & $8.1 \pm 0.1$ & $8.8 \pm 0.1$ & $11 \pm 2$ & $22 \pm 2$ & $24 \pm 1$ & $25 \pm 1$ \\
\hline G/HA30/HA50 & $8.1 \pm 0.4$ & $9.3 \pm 0.2$ & $9.6 \pm 0.1$ & $9.9 \pm 0.3$ & $13 \pm 2$ & $23 \pm 1$ & $26.2 \pm 0.9$ & $27 \pm 1$ \\
\hline
\end{tabular}
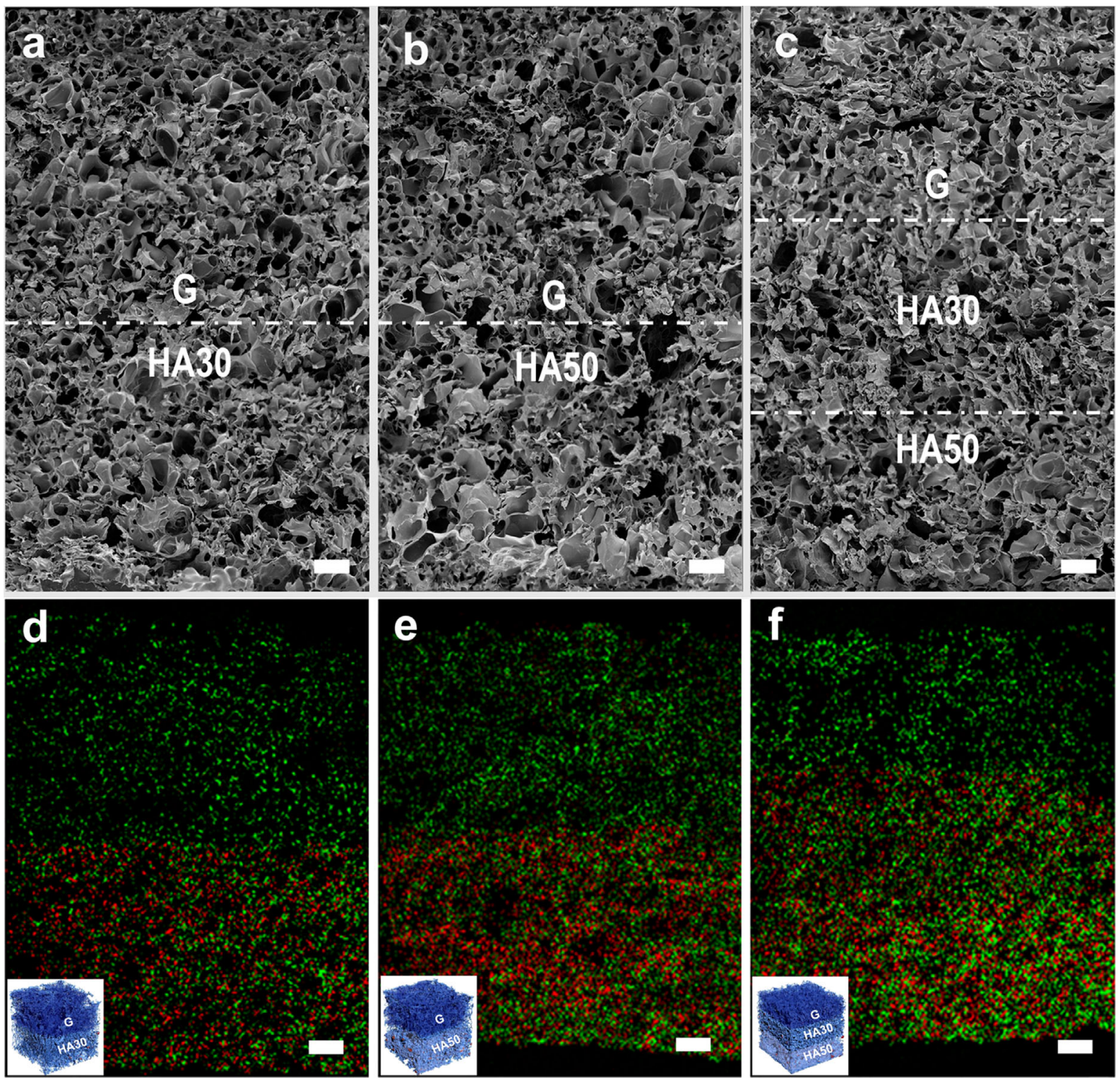

Figure 5. (a-c) Cross-sectional SEM micrographs and (d-f) relative EDS maps of bi- and three-layered scaffolds $(a, d) G / H A 30,(b, e) G / H A 50$, and $(c, f) \mathrm{G} / \mathrm{HA}_{3} \mathrm{O} / \mathrm{HA}_{5} \mathrm{O}$. In the EDS maps, $\mathrm{P}$ is green and $\mathrm{Ca}$ is red, whereas the sketches of the different scaffolds are reported in the inserts. Bars $=500 \mu \mathrm{m}$. 


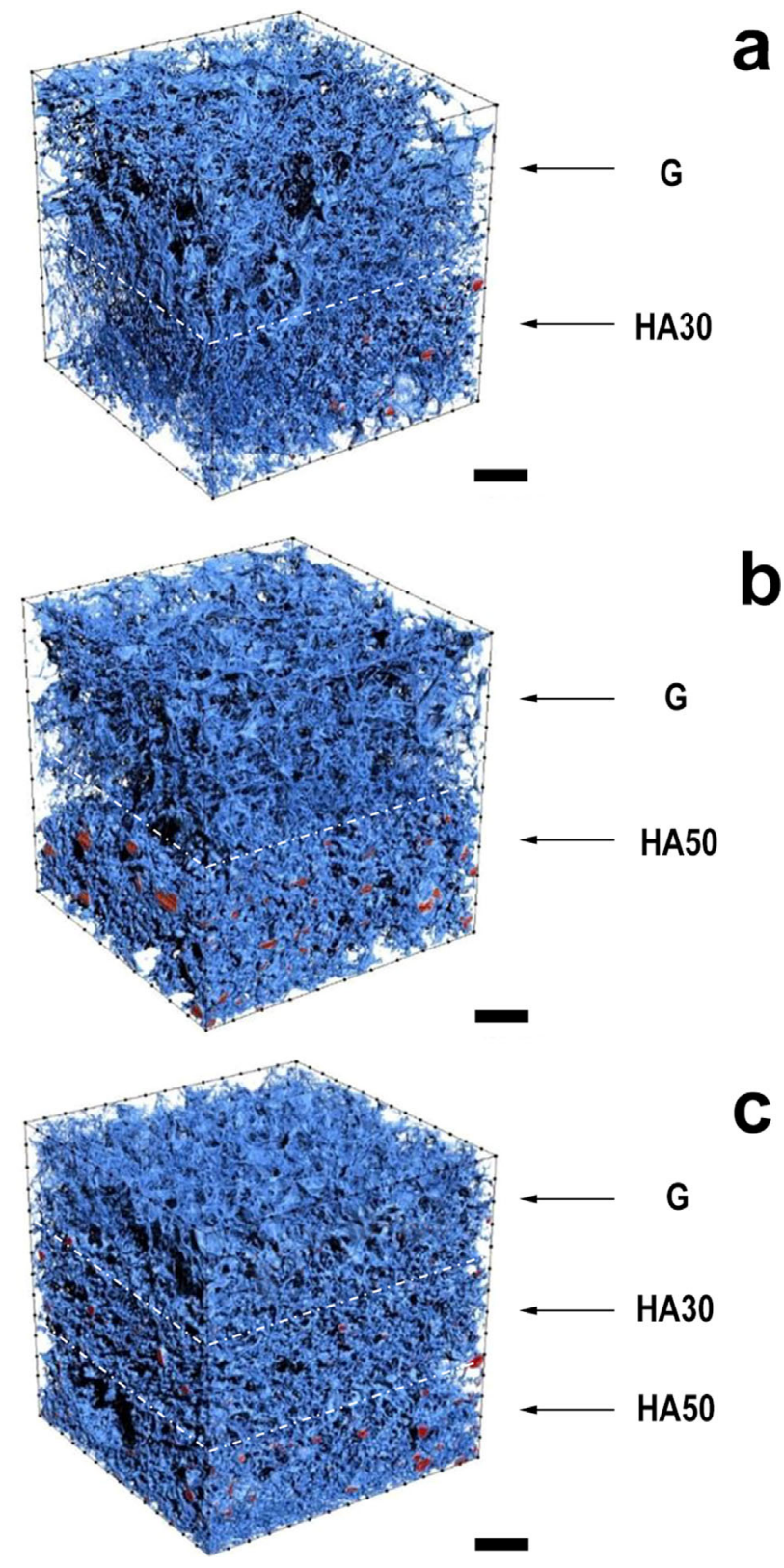

Figure 6. $3 \mathrm{D} \mu-\mathrm{CT}$ representation of bi- and three-layered scaffolds. Bars $=500 \mu \mathrm{m}$.

regenerative medicine as they are the natural cells recruited for osteochondral regeneration. ${ }^{[31]}$ In the present study, we evaluated activity and differentiation of hMSC culture on both chondral and bone sides of bi- and three-layered porous scaffolds up to $14 \mathrm{~d}$. Due to the difficulty to manage different cell cultures simultaneously and to reproduce the physiological microenvironment in vitro, hMSC were previously separately pre-differentiated in chondrogenic and osteogenic medium. Results of bi- and three-layered porous scaffold cultures are compared to those obtained for single cultures onto single-layer scaffolds and to control groups, namely chondrogenic- and osteogenic-differentiated hMSC seeded in single and co-cultures on culture plates.

\subsection{Cell Viability}

All cultures were assayed for cell viability and proliferation by WST1 test. CTR-C and CTR-O show significant higher values of proliferation, both at 7 and $14 \mathrm{~d}$, when tested in cocultures with respect to single-cultures (Figure 7a).

The results obtained for single cultures indicate that single-layer scaffolds improve proliferation rate for both chondrogenic and osteogenic hMSCs. In fact, WST1 displays significant higher values on $\mathrm{G}$ group in comparison to CTR-C (7 and $14 \mathrm{~d}$ ), and on HA30 and HA50 with respect to CTR-O (14 d). The values exhibited by co-cultured cells on bi- and three-layered scaffolds, G/HA30, G/HA30/HA50 (7 and 14 d), and G/HA50 (14 d), are lower than on co-cultured CTR (CTR-C-O group), but generally higher in comparison with single cultures. In agreement with good proliferation data, cells attach and spread both on the gelatin side and on the gelatin/hydroxyapatite side of the scaffolds: chondrogenicand osteogenic-differentiated hMSC exhibit numerous filopodia which extend both on the surface and inside the layers, as shown in Figure 8.

\subsection{Osteogenic-Differentiated hMSC Activity}

ALP, as an early marker of differentiation, and COLL1, the main component of extracellular matrix, were chosen as markers of osteoblastic differentiation. The results of ALP and COLL1 production in control, single, and co-cultures of osteogenic-differentiated hMSC are reported in Figure 7b,c. ALP activity of hMSC-O single cultures are promoted on single-layer scaffolds in comparison to CTRs, whereas COLL1 production does not show significant variations. The levels of both markers appear significantly improved on cocultured CTR-C-O when compared to CTR-O. Moreover cocultures on bi- and three-layered scaffolds show a significantly higher production of ALP at 7 (G/HA30/ HA50) and $14 \mathrm{~d}$ (G/HA30, G/HA50, G/HA30/HA50), and of COLL1 at 7 (G/HA30/HA50) and at $14 \mathrm{~d}$ (G/HA30) when compared to single cultures and CTR-O.

\subsection{Chondrogenic-Differentiated hMSC Activity}

The evaluation of chondrogenic differentiation was performed through the measure of COLL2 and AGC, as markers of the most abundant proteins of extracellular matrix produced by chondrocytes. The chondrogenic-differentiated hMSC (Figure $7 \mathrm{~d}, \mathrm{e}$ ) show significantly higher level of both COLL2 (14 d) and AGC (7 and 14 d) in co-cultures (CTR-C- 


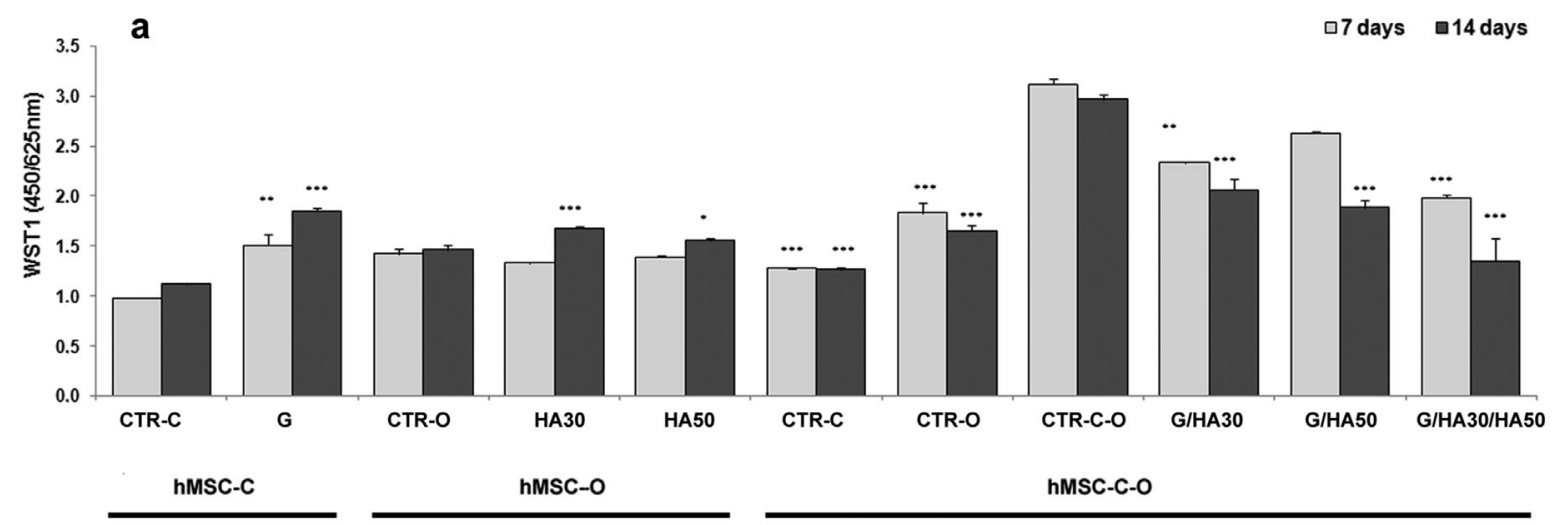

b
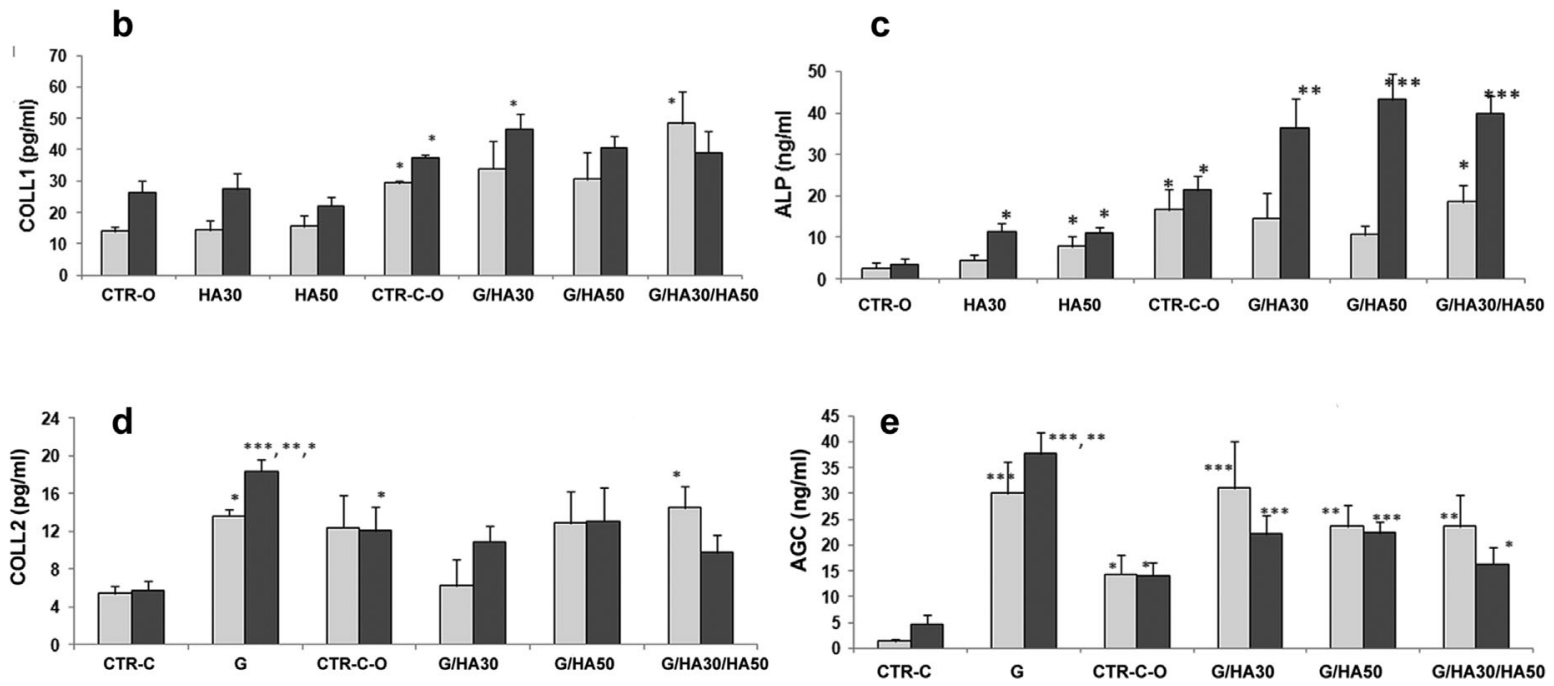

Figure 7. (a) WST1. Effects of materials on the viability of chondrogenic (hMSC-C) and osteogenic (hMSC-O)-differentiated hMSC in single and in co-cultures, compared to CTRs, at $7 \mathrm{~d}$ (light gray bars) and at $14 \mathrm{~d}$ (black bars), assessed by WST1 test. The results are expressed as mean +/-sd $\left({ }^{*} p<0.05 ;{ }^{* *} p<0.005 ;{ }^{* * *} p<0.0005\right) \cdot 7 \mathrm{~d}:{ }^{* * *}$ single CTR-C versus co-cultured CTR-C, ${ }^{* * *}$ single CTR-O versus co-cultured CTR-O; ${ }^{* *} \mathrm{G}$ versus CTR-C; ${ }^{* *} \mathrm{G} / \mathrm{HA} 30$ versus CRT-C-O; ${ }^{* * *} \mathrm{G} / \mathrm{HA} 30 / \mathrm{HA} 50$ versus CRT-C-O; $14 \mathrm{d:}{ }^{* * *}$ single CTR-C versus co-cultured CTR-C, ${ }^{* * *}$ single $\mathrm{CTR}-$ O versus co-cultured CTR-O; ${ }^{* * *} \mathrm{G}$ versus CTR-C; ${ }^{* * *} \mathrm{G} / \mathrm{HA} 30$ versus CTR-O; ${ }^{*} \mathrm{G} / \mathrm{HA} 50$ versus CTR-O; ${ }^{* * *} \mathrm{G} / \mathrm{HA} 3 \mathrm{O}, \mathrm{G} / \mathrm{HA} 50, \mathrm{G} / \mathrm{HA} 30 / \mathrm{HA} 50$ versus CRT-C-O. (b) COLL1 production, and (c) ALP activity of osteogenic hMSC after $7 \mathrm{~d}$ (light gray bars) and $14 \mathrm{~d}$ (black bars) of culture on mono- and

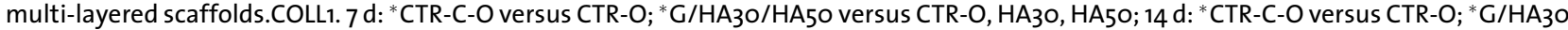

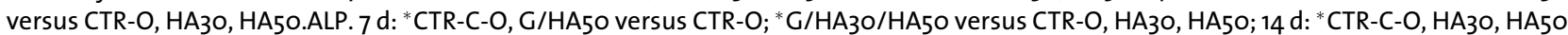
versus CTR-O; ${ }^{* *} \mathrm{G} / \mathrm{HA}_{3} \mathrm{O},{ }^{* * *} \mathrm{G} / \mathrm{HA} 50,{ }^{* * *} \mathrm{G} / \mathrm{HA} 30 / \mathrm{HA} 50$ versus HA30, HA5O. ${ }^{*} \mathrm{G} / \mathrm{HA} 30 / \mathrm{HA} 50$ versus HA5O, CTR-C-O (d) COLL2, and (e) AGC production of chondrogenic hMSC after $7 \mathrm{~d}$ (light gray bars) and $14 \mathrm{~d}$ (black bars) of culture on mono- and multi-layered scaffolds. COLL2. $7 \mathrm{~d}$ : ${ }^{*} \mathrm{G}$ versus CTR-C; ${ }^{*} \mathrm{G} / \mathrm{HA} 30 / \mathrm{HA} 50$ versus CTR-C, HA3O; $14 \mathrm{~d}:{ }^{*} \mathrm{CTR}-\mathrm{C}-\mathrm{O}$ versus CTR-C; $\mathrm{G}$ versus ${ }^{* * *} \mathrm{CTR}-\mathrm{C},{ }^{* *} \mathrm{G} / \mathrm{HA} 30 / \mathrm{HA} 5 \mathrm{O},{ }^{*} \mathrm{HA} 30, \mathrm{HA} 50$ AGC. 7 d: ${ }^{*} \mathrm{CTR}-\mathrm{C}-\mathrm{O}$ versus CTR-C; ${ }^{* * *} \mathrm{G}, \mathrm{G} / \mathrm{HA} 30$ versus CTR-C, ${ }^{* *} \mathrm{G} / \mathrm{HA} 50, \mathrm{G} / \mathrm{HA} 30 / \mathrm{HA} 50$ versus CTR-C; 14 d: ${ }^{*} \mathrm{CTR}-\mathrm{C}-\mathrm{O}$ versus CTR-C; ${ }^{* * *} \mathrm{G}, \mathrm{G} / \mathrm{HA} 3 \mathrm{O}, \mathrm{G} /$ HA50 versus CTR-C, ${ }^{*} \mathrm{G} / \mathrm{HA} 30 / \mathrm{HA} 50$ versus CTR-C; ${ }^{* *} \mathrm{G}$ versus CTR-C-O, G/HA30/HA50; ${ }^{* *} \mathrm{G}$ versus $\mathrm{G} / \mathrm{HA} 30, \mathrm{G} / \mathrm{HA} 50$.

O) than in single cultures (CTR-C). G significantly improves cell synthetic activity for the production of COLL2 when compared to CTR-C, and of AGC with respect to both CTR-C and CTR-C-O, confirming to be a substrate particularly favorable to chondrocytes growth and production of extracellular matrix. ${ }^{[19]}$ No differences can be appreciated in COLL2 production of co-cultures on bi-layered scaffolds when compared to CTR-C-O, whereas values of COLL2 on three-layered scaffolds are higher when compared to CTR-C and G/HA30 at $7 \mathrm{~d}$. AGC production in all co-cultured samples is higher than CTR-C both at 7 and $14 \mathrm{~d}$, but lower than $\mathrm{G}$ group at $14 \mathrm{~d}$.

\section{8. hMSC Gene Expression}

As co-culture of differentiated hMSC implies the simultaneous use of osteoblast and chondrocyte differentiating media, the presence in the in vitro microenvironment of two different culture media may affect cell behavior. For 

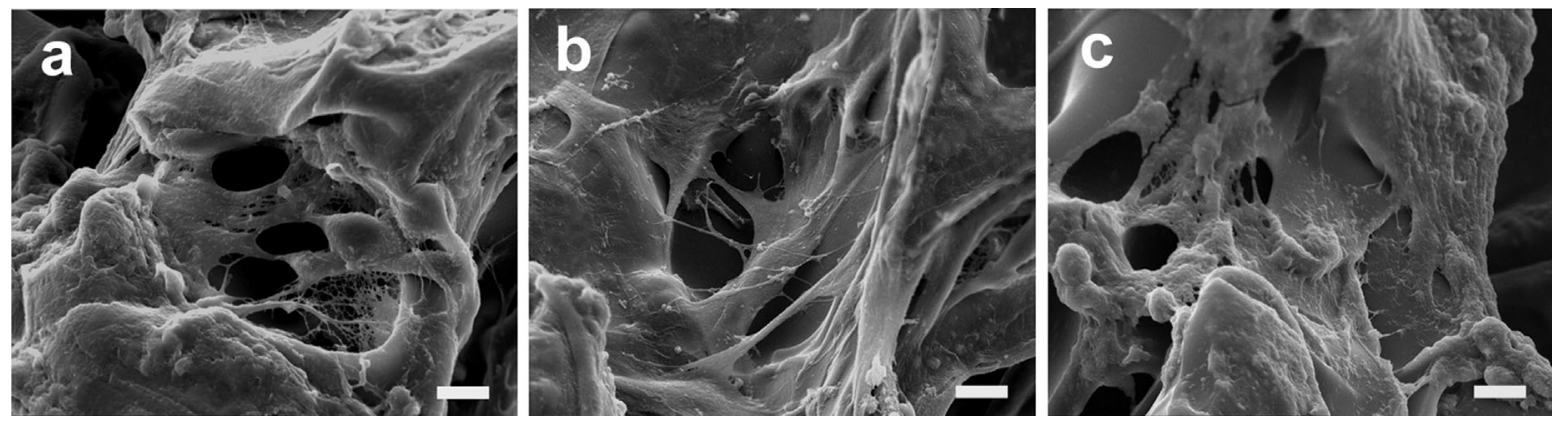

Figure 8. SEM micrographs of hMSCs grown on (a) G, (b) HA3O, and (c) HA50 layers at the end of experimental time. Bars $=10 \mu \mathrm{m}$.

this reason, some representative genes were chosen to assess osteoblastic or chondrogenic differentiation of MSC after $14 \mathrm{~d}$ of co-cultures on bi- and three-layered scaffolds and compared to basal values (Figure 9).

The results indicate that upregulation of the studied genes is strictly related to activity and differentiation of hMSC. RUNX2 is a specific regulator gene of osteoblastic differentiation: it is an essential transcription factor that stimulates the osteoblast lineage from multipotent mesenchymal cells, inducing early osteoblastic differentiation and ALP activity. SOX9 has a role in the control of the different phases during progression of chondrocytes differentiation from undifferentiated MSC. COL1A1 and ACAN are the genes encoding for the corresponding COLL1 and AGC proteins. Data of RUNX2 and COL1A1 activation, and of SOX9 and ACAN gene expressions, show that cocultured hMSC maintain and improve their osteogenic and chondrogenic differentiation with respect to single culture.
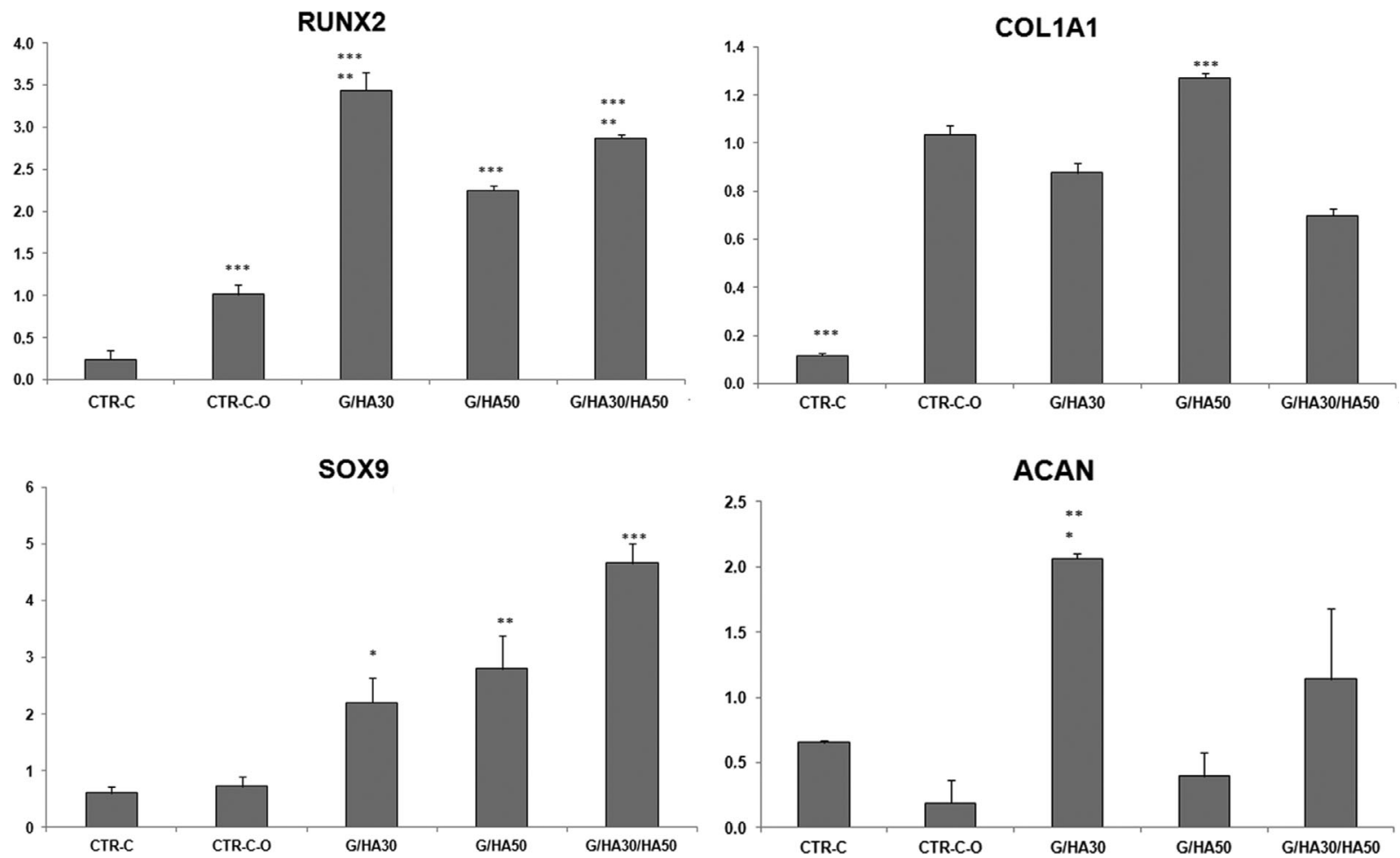

Figure 9. Quantitative real-time PCR analysis of the level of mRNA for RUNX2, COL1A1, SOX9, ACAN of co-cultured-differentiated hMSC on $\mathrm{G} / \mathrm{HA}_{3} \mathrm{O}, \mathrm{G} / \mathrm{HA}_{5} \mathrm{O}$, and $\mathrm{G} / \mathrm{HA}_{3} \mathrm{O} / \mathrm{HA}_{5} \mathrm{O}$, and CTR of single and co-cultures. Their expression was normalized to the GAPDH reference gene. Values are related to CTR basal measure and they are expressed as mean $+/-$ sd of triplicate $\left({ }^{*} p<0.05 ;{ }^{* *} p<0.005 ;{ }^{* * *} p<0.0005\right)$. RUNX2. ${ }^{* * *} \mathrm{CTR}-\mathrm{O}$ versus CTR-C-O, G/HA30, G/HA50, G/HA30/HA50; ${ }^{* * *} \mathrm{CTR}-\mathrm{C}-\mathrm{O}$ versus G/HA30, G/HA50, G/HA30/HA50; * $\mathrm{G} / \mathrm{HA} 30 / \mathrm{HA} 50$ versus G/ HA30, G/HA50 COL1A1. ${ }^{* *}$ CTR-O versus CTR-C-O, G/HA30, G/HA5O, G/HA30/HA5O; ${ }^{* * *} \mathrm{G} / \mathrm{HA} 50$ versus CTR-C-O, G/HA30, G/HA30/HA5O SOX9. ${ }^{*} \mathrm{G} / \mathrm{HA} 30$ versus CTR-O, CTR-C-O; ${ }^{*} \mathrm{G} / \mathrm{HA} 50$ versus CTR-O, CTR-C-O, G/HA3O/HA5O; ${ }^{* *} \mathrm{G} / \mathrm{HA} 30 / \mathrm{HA} 50$ versus CTR-O, CTR-C-O, G/HA3O ACAN. ${ }^{*} \mathrm{G} / \mathrm{HA} 30$ versus CTR-O; ${ }^{* *} \mathrm{G} / \mathrm{HA} 30$ versus CTR-C-O, G/HA5O. 
Differentiation is sustained also in co-cultured samples, as assessed by statistical analysis (Figure 9).

Overall, in vitro results demonstrate that osteogenic and chondrogenic-differentiated hMSC influence each other's behavior, as the parameters evaluated on co-cultures were significantly different from those obtained on single cultures.

\section{Conclusion}

Immersion in gelatin solution followed by freeze-drying proved to be a fast and successful method to prepare multilayered porous 3D scaffolds with graded composition. The gelatin layers at different hydroxyapatite content, which are assembled in the scaffolds in order to mimic the different zones of the osteochondral region, exhibit a high interconnected porosity and tailored mechanical properties. Despite the difficulty to carry on in vitro co-cultures through the simultaneous use of very different media, the results demonstrate that cells are differentiated and able to synthesize their extracellular matrix when cultured together onto tridimensional scaffolds. The composition of each layer, separately evaluated, improves cell differentiation. Moreover, the phenotype of differentiated cells is maintained also in co-cultured, bi-, and tri-layered scaffolds.

Acknowledgements: The authors are very grateful to Dr. Katia Rubini for thermogravimetric analysis. This research has been supported by a grant from the Italian Ministry of Health FIRB $n$. RBAP10MLK7 and by University of Bologna. The authors are also grateful to Rizzoli Orthopaedic Institute and funds $5 \times 1000$ year 2011 .

Keywords: co-cultures; gelatin; hydroxyapatite; multi-layered scaffolds; osteochondral regeneration

[1] K. Shimomura, Y. Moriguchi, C. D. Murawski, H. Yoshikawa, N. Nakamura, Tissue Eng. Part B 2014, 20, 468.

[2] S. Grässel, J. Loren, Curr. Rheumatol. Rep. 2014, 16.

[3] A. R. Poole, T. Kojima, T. Yasuda, F. Mwale, M. Kobayashi, S. Laverty, Clin. Orthop. Relat. Res. 2001, 391 Suppl, S26.

[4] J. M. Oliveira, M. T. Rodrigues, S. S. Silva, P. B. Malafaya, M. E. Gomes, C. A Viegas, I. R. Diaz, J. T. Azevedo, J. F. Mano, R. L. Reis, Biomaterials 2006, 27, 6123.
[5] T. Gotterbarm, W. Richter, M. Jung, S. Berardi Vilei, P. MainilVarle, T. Yamashita, S. J. Breusch, Biomaterials 2006, 27, 3387.

[6] E. Kon, M. Delcogliano, G. Filardo, M. Fini, G. Giavaresi, S. Francioli, I. Martin, D. Pressato, E. Arcangeli, R. Quarto, M. Sandri, M. Marcacci, J. Orthop. Res. 2010, 28, 116.

[7] J. H. Ahn, T. H. Lee, J. S. Oh, S. Y. Kim, H. J. Kim, I. K. Park, B. S. Choi, G. I. Im, Tissue Eng. Part A 2009, 15, 2595.

[8] C. H. Chang, F. H. Lin, C. C. Lin, C. H. Chou, H. C. Liu, J. Biomed. Mater. Res. B Appl. Biomater. 2004, 71, 313.

[9] J. Chen, H. Chen, P. Li, H. Diao, S. Zhu, L. Dong, R. Wang, T. Guo, J. Zhao, J. Zhang, Biomaterials 2011, 32, 4793.

[10] B. Marquass, J. S. Somerson, P. Hepp, T. Aigner, S. Schwan, A. Bader, C. Josten, M. Zscharnack, R. M. Schulz, J. Orthop. Res. 2010, 28, 1586.

[11] L. P. Yan, J. Silva-Correia, M. B. Oliveira, C. Vilela, H. Pereira, R. A. Sousa, J. F. Mano, A. L. Oliveira, J. M. Oliveira, R. L. Reis, Acta Biomater. 2015, 12, 227.

[12] G. Leone, M. D. Volpato, N. Nelli, S. Lamponi, E. Boanini, A. Bigi, A. Magnani, J. Biomed. Mater. Res. Part A 2014, 00A: 000-000. DOI: 10.1002/jbm.a.35389

[13] D. W. Hutmacher, J. T. Schantz, C. X. Lam, K. C. Tan, T. C. Lim, J. Tissue Eng. Regen. Med. 2007, 1, 245.

[14] T. G. Kim, H. Shin, D. W. Lim, Adv. Funct. Mater. 2012, 22, 2446.

[15] J. F. Mano, G. A. Silva, H. S. Azevedo, P. B. Malafaya, R. A. Sousa, S. S. Silva, L. F. Boesel, J. M. Oliveira, T. C. Santos, A. P. Marques, N. M. Neves, R. L. Reis, J. R. Soc. Interface 2007, 4, 999.

[16] M. C. Gómez-Guillén, B. Giménez, M. E. López-Caballero, M. P. Montero, Food Hydrocolloids 2011, 25, 1813.

[17] S. M. Lien, L. Y. Ko, T. J. Huang, Acta Biomater. 2009, 5, 670.

[18] S. Amadori, P. Torricelli, K. Rubini, M. Fini, S. Panzavolta, A. Bigi, J. Mater. Sci. Mat. Med. 2015, 26, 69.

[19] S. Amadori, P. Torricelli, S. Panzavolta, A. Parrilli, M. Fini, A. Bigi, Macromol. Biosci. 2015, 14, 000-000. DOI: 10.1002/ mabi.201500014

[20] Y. S. Choi, S. R. Hong, Y. M. Lee, K. W. Song, M. H. Park, Y. S. Nam, Biomaterials 1999, 20, 409.

[21] A. Bigi, S. Panzavolta, K. Rubini, Chem. Mater. 2004, 16, 3740.

[22] S. Panzavolta, P. Torricelli, S. Amadori, A. Parrilli, K Rubini, E. Della Bella, M. Fini, A. Bigi, J. Biom. Mat. Res. 2013, 101, 3560.

[23] M. Frydrych, C. Wan, R. Stengler, K. U. O’Kelly, B. Chen, J. Mater. Chem. 2011, 21, 9103.

[24] S. Lopa, H. Mandry, Tissue Eng. Part A 2014, 20, 2052.

[25] K. Ishihara, K. Nakayama, S. Akieda, S. Matsuda, Y. Iwamoto, J. Orthop. Surg. Res. 2014, 9, 98.

[26] J. Jang, S. B. Nicoll, H. H. Lu, Biochem. Biophys. Res. Comm. 2005, 338, 762.

[27] R. Nakaoka, S. X. Hsiong, D. J. Mooney, Tissue Eng. 2006, 12, 2425.

[28] T. Cao, K-H. Ho, S. H. Teoh, Tissue Eng. 2003, 9, S103.

[29] H. Da, S. J. Jia, G. L. Meng, J. H. Cheng, W. Zhou, Z. Xiong, Y.J. $\mathrm{Mu}$, J. Liu, PLOS ONE 2013, 8, e 54838.

[30] K. Chen, T. K. H. Teh, S. Ravi, S. L. Toh, J. C. H. Goh, Tissue Eng. Part A 2012, 18, 1902.

[31] A. Cheng, T. E. Hardingham, S. J. Kimber, Tissue Eng. Part $B$ 2014, 20, 257. 